\title{
Investigating Primary Student Teachers' Knowledge and Attitudes towards Alternative Assessment Methods at Princess Nourah bint Abdulrahman University in Saudi Arabia.
}

\author{
Dr. Reem A. Aldegether
}

Dr. NajwanHamdan

\begin{abstract}
:
Teacher education program has an important role in providing student teachers with current practices related to assessment theoretically and practically. The current study aimed to investigate Saudi female student teachers' knowledge and attitudes towards using alternative assessment methods atPrincess Nourah bint Abdulrahman University (PNU). The participants were 105 senior student teachers majoring in primary education at the college of education in Saudi Arabia.To examine the research questions, the participants responded to items that measure their attitudes towards using assessment methods, and they also responded to items that test their knowledge about the methods that define alternative assessment. The researchers utilized descriptive analysis methods using means and standard deviation. Analysis of the relationship between student teachers' attitudes and knowledge were also conducted. The results showed that student teachers have negative attitudes towards using alternative assessment methods and they were unsure about the methods that define alterative assessment. Recommendations were provided for teacher preparation programs educators.
\end{abstract}

Key words: Alterative Assessment- traditional assessment- student teachers

\section{Introduction}

The role of assessment in learning is gaining more attention in recent years. The purpose of assessment is "to strengthen the frequent feedback that students receive about their learning which yield substantial learning gain" ( $p$, 1William, Paul \& Dylan, 1998). This attention is translated intoa movement from traditional assessment towards alternative assessments in the last years. Alternative assessment started being used as a means for educational reform due to the increasing awareness of the influence of testing on curriculum and instruction (Dietel, Herman, and Knuth, 1991). The reason for that is that traditional assessments methods criticized of being indirect and inauthentic. Standardized tests, for instance, which are forms of traditional assessment considered to be one-shot, speed-based, and normreferenced kind of assessment. Law \&Eckes (1995) underlined

\section{1}


the same issue when theyargued that standardize assessment methods are single-occasion tests. That is, they measure what learners can do at a particular time. Test scores cannot tell about the progression of childnor do they tell what particular difficulties students have during the test.

Many studies have shown that most standardized tests assess only the lower-order thinking skills of the learners; they often focus on lower level of cognition skills such as learner's ability of memorization and recalling. In addition, traditional assessment tools require learners to display their knowledge in a predetermined way (Law and Eckes 1995; Brualdi, 1996).In tradition, absence of feedbackmakes students' projects individualized and assessment procedure decontextualized (Bailey, 1998). In her article on alternative assessment, Huerta-Macias (1995) claimed that although traditional forms of assessment can provide somehow suitable measures of students' performance, they often fail to give information about what the students can do in their second language.

Alternative assessments methodsinclude variety of instruments that can be modified in varying situations. These instruments include but not limited to: checklists of students' behavior, products, journals, reading logs, videos of role plays, audio tapes of discussion, self-evaluation questionnaires, work samples, and teacher observations or anecdotal records. All of the different means of assessment help assess higher-order thinking skills (Anthony, Johnson, Mikelson, \& Peerce, 1991; Goodman, 1991; Holt; 1994). They promote the growth and the performance of the studentsthrough providing them with the opportunity to demonstrate what they learned. That is, if a learner fails to perform a given task at a particular time, s/he still has the opportunity to demonstrate his/her ability at a different time and different situations. Since alternative assessment is developed in context and over time, the teacher has a chance to measure the strengths and weaknesses of the students in a variety of areas and situations (Law and Eckes, 1995).Furthermore, authentic assessment tools, such as portfolios, or independent projects, and

\section{2}


journals let learners express their knowledge on the material in their own ways using various intelligences (Brualdi, 1996). At the same time, differentiations of assessment help teachers get authentic information in developing better instructional plans and practices.

Hancock (1994) believed that one of the advantages of alternative assessment is that it gives enough opportunities for the learners to discover that they can complete tasks successfully. Alternative forms of tastings are more student-centered as they involve students in their learning, so that they can control their own language learning (Richards \&Renandya, 2002).For example, language classes that focus on different alternative assessment methods help to evaluate what they learn both in and outside of the language class in a real life situation. Differentiation of assessment encourages new communication, utilizes learnercentered type of learning and teaching, integrates skills, emphasizes on process, and encourages open- ended or multiple types of solutions (Richards \& Renandya, 2002).

Substantial research linked between students' achievement and using alternative assessment methods. In an experimental study that examined the impact of alternative assessment activities on students' academic achievement levels and attitudes, the researchers found that there is a significant difference between the experimental and the control groups with respect to science attitudes and achievement (Kırıkkaya and Vurkaya, 2011).Also, Alsofyani (2010) conducted a study examining the effect of using alternative assessment methods on students' achievement in Islamic studies class. The results showed that students who were exposed to different means of assessment have higher score than those who only were exposed to traditional ways of assessment.

Bound \& Flachikov (2006) summarized the central feature of alternative assessment methods when they stated: "Preparing students for lifelong learning involves preparing them for the tasks of making complex judgments about their own work and that of others and for making decision in the uncertain and unpredictable

\section{3}


circumstances in which they will find themselves in the future." ( $P$, 402)

Recentstudies, however, have shown that most current practices of higher education do not persist on the need for students to evaluate or reflect on their own thinking (Watt, 2005). Therefore, The need for more authentic assessment have been called for to fulfill lifelong learning that connects what students take to their everyday live ( Dochy\&Morkerke, (1998).Guskey (2000) argues that teachers who provide useful and meaningful feedback provide students with opportunity to reflect on their learning and progress. Teachers apt to remember that to be able to achieve different learning outcomes they have to verify the way they evaluate their students (Shepard, 2000).

Unfortunately, substantial studies revealed that most current teachereducation programs in the Arab world in general and in Saudi Arabia in specific donot prepareprimary student teachers professionally (Abdullah, 2001; Abdulrahman, 2002; Mohammad, 2006 ;Abdulrahman \& Hassan, 2004; Algamdi, 2010). Many graduates from teacher education programslackthe necessary skills, knowledge, and dispositions to succeed. Alomar (2008) points out that many of students graduatedfrom teacher education programs lacking the basic standards of effective teaching, learning, and assessment. For example, Aljussar (2004) conducted a study evaluating teacher education program in Kuwait; she found incoherency between the theoretical and the practical parts of what student teachers experience during their years of preparation. Mohammad, (2006) also conducted an evaluative study about the reality of teacher education programs in Egypt; Mohamamd study yielded similar conclusion. The question becomes whether or not the current practices in teacher preparation programsconceive and execute new ways of assessing students. Do they equip students with these tools of assessment through teaching and the curriculum?

\section{Statement of the problem}

Before 1990's our testing and assessment were based on behaviorist views of cognition and improvement, but after 1990's it was suggested that some alternative ways of testing and

\section{4}


assessing are needed to evaluate a person's performance (Hancock, 1994). It has been agreed by many studies on the importance of using different means to evaluate students' performances. Furthermore, it has been proven by many studies that using different assessmentmethods in everyday teaching will improve students' thinking skills, foster reflective thinking, and help students become more responsible of their own learning. Unfortunately, little attention is given to teacher preparation program and its role in preparing prospective teachers to use alternative assessment methods in their teaching. There is limitedliterature that investigates primary Saudi perspective teachers' attitudes towards using alternative assessment methods and their knowledge of the methods that make up alternative assessment. The current study aims to broaden the knowledge toward that issue.

\section{Significance of the study}

The findings of this study are expected to shed the light on students' teacher attitude and knowledge about using alternative assessment methods. The findings may also give student teachers more insights on their awareness of alternative assessment methods, such as portfolios, journals, presentations and checklists in teaching and assessing their students. Furthermore, faculty members, program leaders, and curricula planners may also find the results of this study important to reconsider the different methods of assessing students.

\section{The purpose of the study}

The purpose of the study is to investigate female students' teachers' attitudes and knowledge towards using different alternative assessment in their future teaching.

\section{Research Questions:}

The present study investigates the following questions:

1. What are the attitudes of primary student teachers at Princess Nourah bint Abdulrahman University about using alternative assessment methods in their teaching?

\section{5}


2. Are primary student teachers at Princess Nourah bint Abdulrahman University familiar with alternative assessment methods as identified by current literature?

3. Is there a relationship between primary student teachers' knowledge of alternative assessment methods and their attitudes towards it at Princess Nourah bint Abdulrahman University?

\section{Study limitation}

The present study is limited to Saudi female student teachers majored in primary education at Princess Nourah bint Abdulrahman University.

\section{Methodology and Instruments}

The researchers utilized descriptive design method to achieve the main purpose of the study. The researchers chose an explanatory survey approach for two reasons. First, due to the limited knowledge alternative assessment and elementary education in Saudi Arabia, the researchers chose to explore this topic to establish foundational knowledge about this issue in Saudi primary education. Second, surveys are typical method that is useful for investigating a variety of educational problems and issues. They usually are used to assess attitudes, opinions, preferences, practices, or procedures (Gay \& Airasin, 1992). Therefore, this design was chosen to help the researchers accomplish the objectives of the study.

The research instruments were:

1. Attitude Questionnaire: This instrument was developed by the researchers to investigate the students' attitudes towards alternative assessment methods. The questionnaire contains twenty items that were intended to elicit the subjects' opinions and beliefs on a five -point Likert scale (i.e. strongly agree 5 , agree 4 , neutral 3 , disagree 2 , strongly disagree 1 ). Students were asked to choose the answer which mostly represented their beliefs and opinionsabout alternative methods (See Appendix A).

2. Achievement Test: The purpose of the test was to find out student teachers' knowledge of the definition, importance and

\section{6}


the types of alternative assessment methods. The test consisted of twenty items. (See appendix B)

To answer the first question, items 1 through 20 were utilized. Mean score within the range of 1 to 2.5 indicated negative attitude toward using alternative assessment methods in their teaching. Mean scores of 2.5 to 3.5 indicated a neutral attitude toward using alternative assessment methods. And mean scores within the range of 3.5 to 5 indicated a positive attitude toward using alternative assessment methods. Descriptive analysis of means and standard deviations were used to present the attitudes scale.

The second question was consisted of twenty items. Each item is a statement that represents a definition of an alternative assessment method. The participants were asked to identify these methods by choosing the correct definition to each alternative assessment term. Total scores ranging from 0.00 to 6.7 indicated an inaccurate knowledge about alternative assessment methods. Total scores ranging from 6.7 to 13.7 of the total scores indicated that the participants have uncertain knowledge of about alternative assessment methods; and total scores ranging from 13.7 to 20indicate that perspective teachers have an accurate knowledge about alternative assessment methods. Also, descriptive analysis of mean and standard deviation were used to analyze the knowledge scale.

The last analysis conducted in this study used correlation coefficient to identify the relationship between the participants' attitude towards alternative assessment methods and their knowledge about these methods.

\section{Participants and Sampling}

The target population of the study was senior primary student teachers in the college of education at Princess Nourah bint Abdulrahman in Saudi Arabia. There were 105 students who participated in this study. All of targetparticipants were seniors who were in their last semester before beginning their internships in schools as a part of their training program requirements.

\section{Validity and Reliability of the Instruments:}

The knowledge test and the attitudequestionnaire were validated by a jury of experts consisting of university instructors,

\section{7}


English language supervisors, and well qualified teachers. Their recommendations and comments were taken into account in modifying the instruments before they were used. The experts' comments and suggestions on the original version included: deleting overlapping items, making some editing corrections and forming the questions in a clearer and more direct way. The instruments were finally modified as suggested resulting in a twenty item knowledge test andin a twenty item questionnaire, which later approved by all the experts.

To establish the reliability of the knowledge test, it was applied to a pilot sample from outside the population of the study; the sample consisted of seventeen students. Two weeks later, the test was applied again. Then the correlation coefficient was 0.95.This value was considered satisfactory to apply it to the sample of the study later on.

\section{Results}

The purpose of the study was to investigate female students' teachers' attitude and knowledge toward using different alternative assessment in their teaching through answering the following questions:

1. What are the attitudes of primary student teachers at Princess NourahbintAbdulrahman University about using alternative assessment methods in their teaching?

2. Are primary student teachers at Princess Nourah int bdulrahman University familiar with alternative assessment methods as identified by current literature?

3. Is there a relationship between primary student teachers' knowledge of alternative assessment methods and their attitudes towards it at Princess Nourah bint Abdulrahman University

\section{Research Question one}

Data analysis revealed that the total mean score of the opinion scale fell in the lower range of the attitude scale $(M=2.34, S D=$ .34). This indicates that senior female student teachers at Princess Nourah bint Abdulrahman University hold negative attitudes towards using alternative assessment methods in their teaching.

\section{8}


Number 60 , April , 2015

Table 1 : Descriptive Statistics for the opinion Scale

\begin{tabular}{|c|c|c|c|}
\hline Dependent Variable & $\mathbf{N}$ & Mean & SD \\
\hline Total & $\mathbf{1 0 5}$ & $\mathbf{2 . 3 4}$ & $\mathbf{. 3 4}$ \\
\hline
\end{tabular}

Table 2 summarizes the means (M) and standard deviations (SD) for all the items in the opinion scale.

The greatest influence on the attitude scale is shown by students' response to item 14 that states "I get upset when I think about having to answer a questionnaire." ( $\mathrm{M}=2.94$, $\mathrm{SD}=1.07$ ), $54.7 \%$ of those who responded to this item strongly agree with this statement. Whereas item 11 that states "I feel embarrassed when I make presentations." received the lowest score on the opinion scale $(\mathrm{M}=1.72, \mathrm{SD}=.87)$.

Table 2 : Mean and standard deviation of the attitude toward using alternative assessment methods

\begin{tabular}{|c|c|c|c|c|}
\hline Q & Valid & Missing & Mean & Std. Deviation \\
\hline q14 & $\mathbf{1 0 4}$ & $\mathbf{0}$ & $\mathbf{2 . 9 4}$ & $\mathbf{1 . 0 7 8}$ \\
\hline q18 & $\mathbf{1 0 4}$ & $\mathbf{0}$ & $\mathbf{2 . 9 3}$ & $\mathbf{1 . 0 0 7}$ \\
\hline q15 & $\mathbf{1 0 4}$ & $\mathbf{0}$ & $\mathbf{2 . 9 2}$ & $\mathbf{1 . 0 7 7}$ \\
\hline q16 & $\mathbf{1 0 4}$ & $\mathbf{0}$ & $\mathbf{2 . 7 2}$ & $\mathbf{0 . 8 6 4}$ \\
\hline q17 & $\mathbf{1 0 4}$ & $\mathbf{0}$ & $\mathbf{2 . 6 1}$ & $\mathbf{1 . 0 9 2}$ \\
\hline q5 & $\mathbf{1 0 4}$ & $\mathbf{0}$ & $\mathbf{2 . 4 8}$ & $\mathbf{1 . 0 1 4}$ \\
\hline q4 & $\mathbf{1 0 4}$ & $\mathbf{0}$ & $\mathbf{2 . 4 4}$ & $\mathbf{0 . 8 1}$ \\
\hline q12 & $\mathbf{1 0 4}$ & $\mathbf{0}$ & $\mathbf{2 . 4 4}$ & $\mathbf{0 . 9 5 4}$ \\
\hline q20 & $\mathbf{1 0 4}$ & $\mathbf{0}$ & $\mathbf{2 . 4 4}$ & $\mathbf{0 . 9 4 3}$ \\
\hline q6 & $\mathbf{1 0 4}$ & $\mathbf{0}$ & $\mathbf{2 . 4 1}$ & $\mathbf{0 . 9 4 1}$ \\
\hline q7 & $\mathbf{1 0 4}$ & $\mathbf{0}$ & $\mathbf{2 . 3 9}$ & $\mathbf{0 . 9 7}$ \\
\hline q13 & $\mathbf{1 0 4}$ & $\mathbf{0}$ & $\mathbf{2 . 2 9}$ & $\mathbf{0 . 9 5 2}$ \\
\hline q8 & $\mathbf{1 0 4}$ & $\mathbf{0}$ & $\mathbf{2 . 1 3}$ & $\mathbf{0 . 9 2 1}$ \\
\hline q10 & $\mathbf{1 0 4}$ & $\mathbf{0}$ & $\mathbf{2 . 1 3}$ & $\mathbf{0 . 9 8 2}$ \\
\hline q2 & $\mathbf{1 0 4}$ & $\mathbf{0}$ & $\mathbf{2 . 0 8}$ & $\mathbf{0 . 8 5 6}$ \\
\hline q9 & $\mathbf{1 0 4}$ & $\mathbf{0}$ & $\mathbf{2 . 0 7}$ & $\mathbf{0 . 9 2 7}$ \\
\hline q3 & $\mathbf{1 0 4}$ & $\mathbf{0}$ & $\mathbf{1 . 9 5}$ & $\mathbf{0 . 8 8 5}$ \\
\hline q19 & $\mathbf{1 0 4}$ & $\mathbf{0}$ & $\mathbf{1 . 9}$ & $\mathbf{1 . 0 2 9}$ \\
\hline q1 & $\mathbf{1 0 4}$ & $\mathbf{0}$ & $\mathbf{1 . 8 8}$ & $\mathbf{0 . 6 5 8}$ \\
\hline q11 & $\mathbf{1 0 4}$ & $\mathbf{0}$ & $\mathbf{1 . 7 2}$ & $\mathbf{0 . 8 7 5}$ \\
\hline \multicolumn{4}{|c|}{} \\
\hline
\end{tabular}




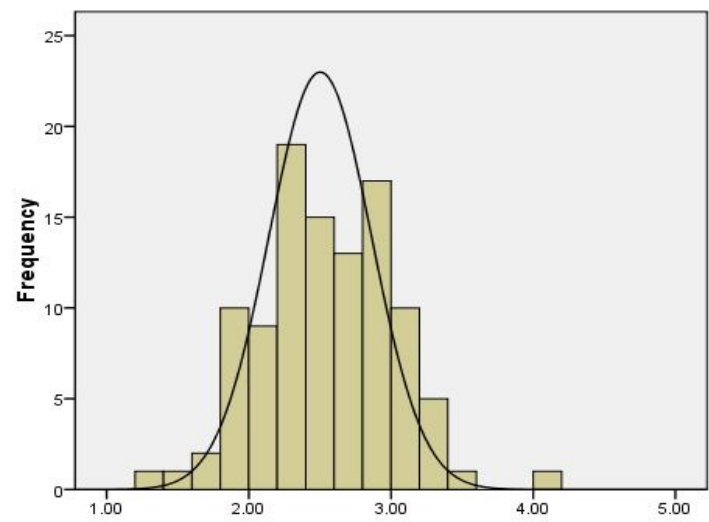

\section{Research Question Two}

Table 3 : criptive Statistics for Knowledge Scale

\begin{tabular}{|c|c|c|c|}
\hline Dependent Variable & N & Mean & SD \\
\hline $\begin{array}{c}\text { Total of the Correct } \\
\text { Answers }\end{array}$ & $\mathbf{1 0 5}$ & $\mathbf{1 0 . 4 0}$ & $\mathbf{2 . 6 5}$ \\
\hline
\end{tabular}

Table 4: Frequencies of the Total Correct Answered.

\begin{tabular}{|c|c|c|c|c|c|}
\hline & & Frequency & Percent & $\begin{array}{l}\text { Valid } \\
\text { Percent }\end{array}$ & $\begin{array}{c}\text { Cumulative } \\
\text { Percent }\end{array}$ \\
\hline \multirow{13}{*}{ Valid } & 3.00 & 2 & 1.9 & 1.9 & 1.9 \\
\hline & 6.00 & 5 & 4.8 & 4.8 & 6.7 \\
\hline & 7.00 & 7 & 6.7 & 6.7 & 13.3 \\
\hline & 8.00 & 13 & 12.4 & 12.4 & 25.7 \\
\hline & 9.00 & 10 & 9.5 & 9.5 & 35.2 \\
\hline & 10.00 & 18 & 17.1 & 17.1 & 52.4 \\
\hline & 11.00 & 15 & 14.3 & 14.3 & 66.7 \\
\hline & 12.00 & 6 & 5.7 & 5.7 & $\overline{72.4}$ \\
\hline & $\mathbf{1 3 . 0 0}$ & 17 & 16.2 & 16.2 & 88.6 \\
\hline & 14.00 & 6 & 5.7 & 5.7 & 94.3 \\
\hline & 15.00 & 5 & 4.8 & 4.8 & 99.0 \\
\hline & 16.00 & 1 & 1.0 & 1.0 & 100.0 \\
\hline & Total & 105 & 100.0 & 100.0 & \\
\hline
\end{tabular}

The sample mean score fell within the upper range of uncertain general knowledge, $(\mathrm{M} 10.40=, \mathrm{SD}=2.65)$. This finding indicates that female student teachers at Princess NourahbintAbdulrahman University were unsure about alternative assessment methods as 
identified by current literature. Table 2 summarizes frequencies of the total correct answer.

Figure (2)

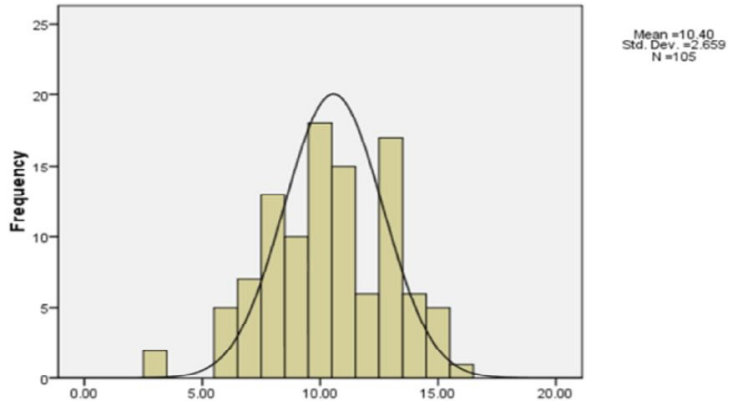

\section{Research Question Three}

The third question asks about the relationship between primary student teachers' knowledge of alternative assessment methods and their attitudes towards it. The Pearson correlation ( $r$ ) was used to answer this question. The data revealed that there is a significant correlation between prospective teachers' attitudes about alternative assessment methods and their knowledge, $r$ $=279$. $p=004$. This finding suggests that prospective teachers who have inaccurate knowledge about different alternative methods have negative attitude about using different alternative assessment methods in their teaching. The result also suggests that negative attitude of students teachers is due to their lack of knowledge about alterative assessment methods.

Table 5 : Pearson Correlation Perspective teachers' opinion/attitude and Knowledge

\begin{tabular}{cccc}
\hline Variable & $\mathrm{N}$ & $\begin{array}{c}\text { General } \\
\text { Knowledge }\end{array}$ & Sig.( 2-tailed) \\
\hline Attitude & 105 & .279 & .004 \\
\hline
\end{tabular}

\section{Discussion}

The results revealed that senior female student teachers hold negative attitudes towards using alternative assessment methods in their teaching. This finding is consistent with other research studies on primary school teachers 'attitudes towards assessment which came to the conclusion that most teachers' attitudes are at

\section{1}


an average or low level (Watt, 2005; Yang, 2007; INTO, 2008; Metin, 2011; Ghazali, Yaakub, \&Mustam, 2012). One reason could be that some teachers might consider alternative assessment methods to be time-consuming and that they ignore pupil writing skills. Other reasons could be the differences in the social, political, knowledge, experience, and cultural context that could affect teachers' attitudes towards assessment. It is also possible that student teachers may feel anxious and resistant towards using new ways of assessment due to their unfamiliarly with these methods and how they can apply them. Another reason could be related to concerns about the potential subjectivity of alternative assessment methods and that they are being unreliable.

Results showed that female student teachers were unsure about alternative assessment methods as identified by current literature. One reason could contribute to this results is the absence of training programs which familiarize student teachers with the alternative assessment methods and the way of using them effectively in classrooms. Research has shown that teachers need training in assessment techniques and inadequate training has forced teachers to use traditional methods of assessment. (Stiggins, 2001; Campell, Murphy, \& Holt, 2002; Mertler, 2003; Hill, 2006; Yang, 2007; INTO, 2008; Birgin \& Baki, 2009; Guerin, 2010; Tante, 2010; Alkharusi et al., 2012; Ghazali et al., 2012; Tangdhanakanond\&Wongwanich, 2012). Another possible reason could be that student teachers did not experience different means of assessments and evaluation to their work.This may also indicate that student teachers lack the knowledge and the skill of using different types of alternative assessment methods effectively

When researchers analyzed the correlation between student teachers attitudes and knowledge, they found out that there is a significant correlation between their attitudes and knowledge. It means that student teachers' negative attitudes towards alternative assessment methods is influenced by their unfamiliarity with the ways of imposing these methods into their teaching. It's also possible that negative attitudes towards alternative

\section{2}


assessment is caused by their insufficient knowledge about alternative assessment during their study. Researchers reported some factors affecting student teachers attitudes and implementation of different means of assessment. Some of the reported factors are difficulty of implementation, time constraints, difficulty of classroom management, subjectivity of grading , inadequate training, large class size, and time-consuming activities., and heavy workloads (Watt, 2005; Yu-Ching, 2008; Alkharusi et al., 2012; Ghazali et al., 2012; Tangdhanakanond \& Wongwanich, 2012I; INTO, 2008; Yu-Ching, 2008; Guerin, 2010).

It can be concluded from the results of this study that faculty members and professors didn't encourage their student teachers to explore and try new ways of assessment by providing them with supporting learning atmosphere and variety of assessment tools. Researchers also concluded from the results that student teachers were not given the opportunity to discover and feel the importance of using variety of methods to meet all students' differences.

\section{Recommendations}

Based on the above mentioned results, the researchers recommend the following:

1. Teachers of English should practice and encourage their students to use alternative assessment methods.

2. The Ministry of Education should emphasize using alternative assessment methods not only in the Teacher's Book, but also in supervising teachers and in authentic assessment. Therefore, there may be a need for more workshops for teachers on how to use alternative assessment methods more effectively.

3. Other researchers need to conduct further studies on teachers' usage of different types of alternative assessment methods.

4. Other researchers need to conduct long term studies on the effectiveness of using different types of alternative

\section{3}


assessment methods in other context and with different teachers.

5. Higher education policy makers should work to make a standardized alternative assessment system in higher education system in Saudi Arabia.

\section{References}

- Bailey, K. M. (1998). Learning about language assessment: dilemmas, decisions, and directions. Heinle\&Heinle: US.

- Brualdi, A. (1998). Implementing performance assessment in the classroom. Practical Assessment, Research \&Evaluation, 6(2). Available online: http://ericae.net/pare/getvn.asp? $v=6 \& n=2$

- BuluşKırıkkaya, E. and Vurkaya, G. (2011). The effect of using alternative assessment activities on students' success and attitudes in science and technology course. Educational Sciences: Theory \& Practice. 11(2), 885-1004.

- Boud, david.\&Falchikov, Nancy (2006). Aligningassessment with long-term learning. Assessment and evaluation in higher educationVol.31,No.o4, August 2006,pp.399-413.

- Clarke, S. (2001). Unlocking Formative Assessment: Practical strategies for enhancing pupils' learning in the primary classroom. London: Hodder\& Stoughton.

- Dietel, R. J., Herman, J. L., \& Knuth, R. A. (1991). What does research say about assessment? NCREL, Oak Brook. Available online: http://www.ncrel.org/sdrs/areas/stw_esys/4assess.htm

- Law, B. \&Eckes, M. (1995). Assessment and ESL. Peguis publishers: Manitoba, Canada.

- Hancock, C.R. (Ed.). (1994). "Teaching, testing, and assessing: Making the connection. Northeast Conference Reports." Lincolnwood, IL: National Textbook Co.

- Huerta-Macias, A. (1995). Alternative assessment: Responses to commonly asked questions. TESOL Journal, 5(1): 8-11.

- Richards, J. C. and W. A. Renandya. (eds.). 2002.Methodology in Language Teaching: An Anthology of Current Practice. Cambridge: Cambridge University Press.

- Simonson M., Smaldino, S, Albright, M. and Zvacek, S. (2000). Assessment for distance education (ch 11). Teaching and Learning at

\section{4}


a Distance: Foundations of Distance Education. Upper Saddle River, NJ: Prentice-Hall.

- Watt, Helen M. G.; (2005). "Attitudes to the Use of Alternative Assessment Methods in Mathematics: A Study with Secondary Mathematics Teachers in Sydney, Australia." Educational Studies in Mathematics 58 (1): 21-44.

- Watt, H. (2005). Attitudes to the use of alternative assessment methods in Mathematics: A study with secondary

- mathematics teachers in Sydney, Australia. Educational Studies in Mathematics, 58, 21-44. http://dx.doi.org/10.1007/s10649-005-3228$\mathrm{Z}$

- Yang, T. (2007). Factors affecting EFL teachers' classroom assessment practices of young language learners

- (PhD thesis, The University of Iowa, U.S.).

- Irish National Teachers' Organization (INTO). (2008). Assessment in the primary school. Discussion document

- and proceedings of the consultative conference on education. Dublin: INTO.

- Metin, M. (2011). The examinations of teachers' attitude towards performance assessment with respect to the

- different variables. Energy Education Science and Technology Part B: Social and Educational Studies, 3(3), 269-284.

- Ghazali, N., Yaakub, B., \&Mustam, A. (2012). "Why do we need to change?" Teachers' attitude towardsschool-based assessment system. SCR London's First International Conference on Social science andHumanities in the Islamic World (28-30 May 2012).

- Yu-Ching, C. (2008). Elementary school EFL teachers' beliefs and practices of multiple assessments. Reflection son English Language Teaching, 7(1), 37-62.

- Tangdhanakanond, K., \&Wongwanich, S. (2012). Teacher attitude and needs assessment concerning the use of student portfolio assessment in Thailand's educational reform process. International Journal of Psychology, 10, 7-8.

- Guerin, E. (2010). Initial findings from a pilot Italian study of EL teachers' stated language assessment knowledge-base and needs. Papers from the Lancaster University Postgraduate Conference in Linguistics \&Language Teaching, Vol. 4: Papers from LAEL PG.

\section{5}


- Stiggins, R. (2001). The unfulfilled promise of classroom assessment. Educational measurement. Issues and Practice, 20(3), 515. http://dx.doi.org/10.1111/j.1745-3992.2001.tb00065.x

- Campell, C., Murphy, J., \& Holt, J. (2002). Psychometric analysis of an assessment literacy instrument: Applicability to pre-service teachers. Paper presented at the annual meeting of the Mid-Western Educational Research Association, Columbus, OH.

- Mertler, C. (2003). Pre-service versus in-service teachers' assessment literacy: Does classroom experience makea difference? Paper presented at the annual meeting of the Mid-WesternEducational Research Association, Columbus, OH (15 Oct. 2003).

- Hill, M. (2006). Comparing apples with pears. Teacher knowledge about assessment and its impact on their practices. Paper presented at the British Educational Research Association Annual Conference, Universityof Warwick (6-9 Sept. 2006).

- Birgin, O., \&Baki, A. (2009). An investigation of primary school teachers' proficiency perceptions about measurement and assessment methods: The case of Turkey. Procedia Social and Behavioral Sciences, 1,681-685. http://dx.doi.org/10.1016/j.sbspro.2009.01.119

- Guerin, E. (2010). Initial findings from a pilot Italian study of EL teachers' stated language assessment knowledge-base and needs. Papers from the Lancaster University Postgraduate Conference in Linguistics \& Language Teaching, Vol. 4: Papers from LAEL PG.

- Tante, A. (2010). The purpose of English language teacher assessment in the English-speaking primary school in Cameroon. ELTED, 13. Al-Kharusi, H.,

- Aldhafri, S., Alnabhani, H., \&Alkalbani, M. (2012). Educational assessment attitudes, competence, knowledge, and practices: An exploratory study of Muscat teachers in the Sultanate of Oman. Journal of Education and Learning, 1(2).

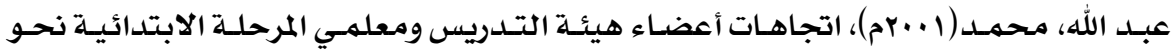

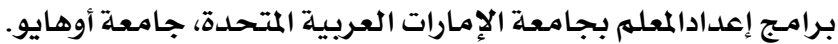

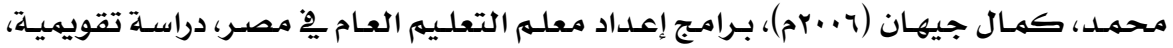

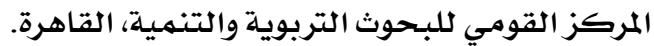

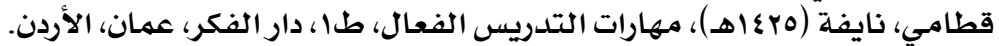

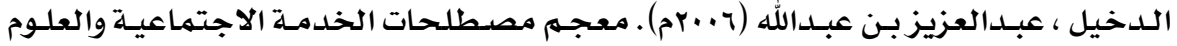

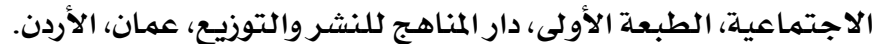

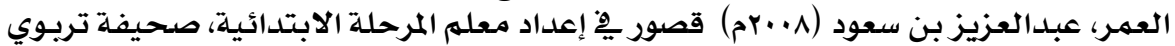

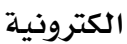

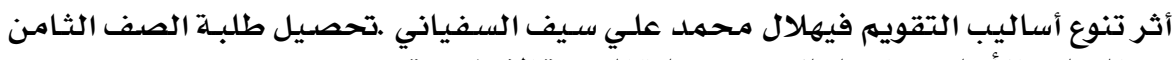
من التعليم الأساسي واتجاهاتهم نحو مادة التربية الإسلامية. 


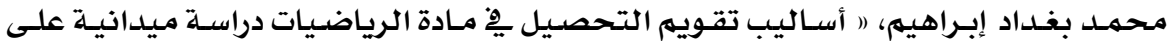

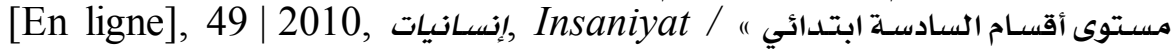
mis en ligne le 16 août 2012, consulté le 30 août 2014. URL : http://insaniyat.revues.org/4

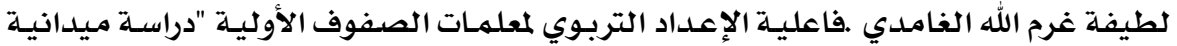

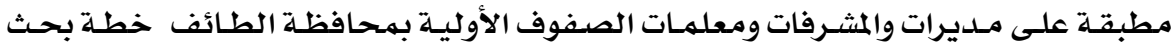

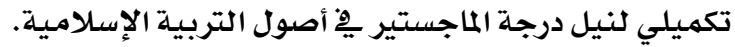

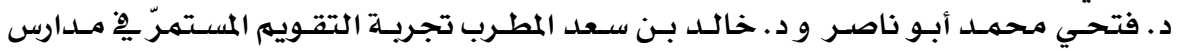

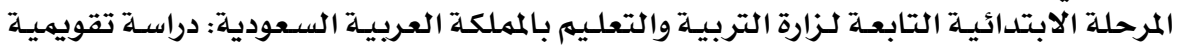

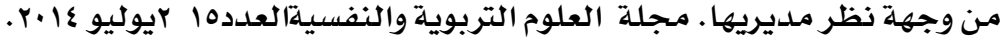

\title{
"استطلاع مدى همرفة المعلمات الطالبات للمهرحلة الابتدائية بطرائق

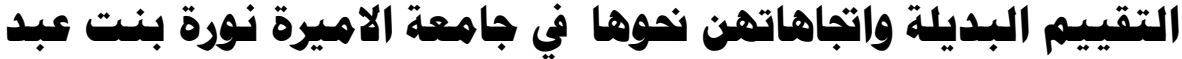 الرحمن في المملكة العربية السعودية فئية
}

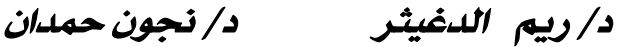

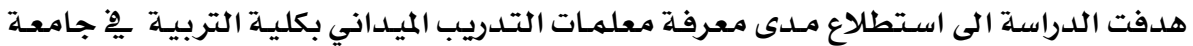

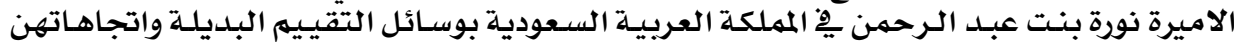

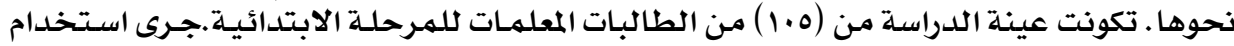

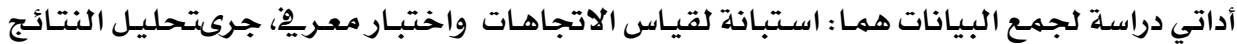

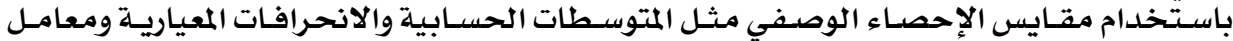

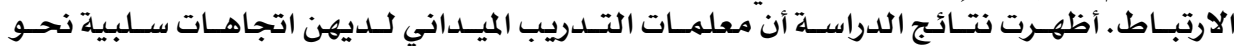

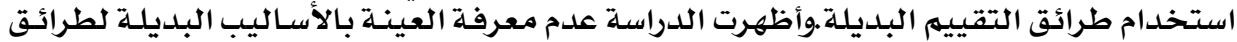

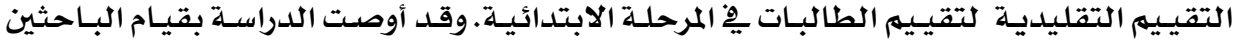

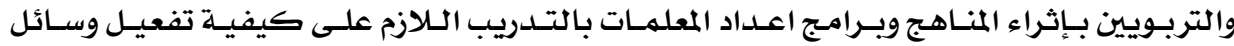

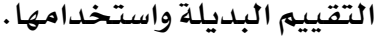

الكلمات المفتاحية: الطالبات المعلمات-طرائق التقييم البديلة- طرائق التقييم التقليدية 